\title{
Hot-Wire Chemical Vapour Deposition for Silicon Nitride Waveguides
}

\author{
T. Domínguez Bucio ${ }^{\mathrm{a}}$, A. Tarazona ${ }^{\mathrm{a}}$, A. Z. Khokhar ${ }^{\mathrm{a}}$, G. Z. Mashanovich ${ }^{\mathrm{a}}$ and F. Y. \\ Gardes $^{\mathrm{a}}$ \\ ${ }^{a}$ Optoelectronics Research Centre, University of Southampton, Highfield Campus, \\ Southampton SO171BJ, UK
}

\begin{abstract}
In this work, we demonstrate the use of hot-wire chemical vapour deposition (HWCVD) as an alternative technique to grow $\mathrm{SiN}$ layers for photonic waveguides at temperatures $<400^{\circ} \mathrm{C}$. In particular, the effect of the ammonia flow and the filament temperature on the material structure, optical properties and propagation losses of the deposited films was investigated. SiN layers with good thickness uniformity, roughness as low as $0.61 \mathrm{~nm}$ and $\mathrm{H}$ concentration as low as $10.4 \times 10^{21}$ atoms $/ \mathrm{cm}^{3}$ were obtained. Waveguides fabricated on the studied materials exhibited losses as low as 7.1 and $12.3 \mathrm{~dB} / \mathrm{cm}$ at 1310 and $1550 \mathrm{~nm}$ respectively.
\end{abstract}

\section{Introduction}

Silicon nitride ( $\mathrm{SiN}$ ) layers are typically deposited by low-pressure chemical vapour deposition (LPCVD) and plasma-enhanced chemical vapour deposition (PECVD). The issue with these deposition techniques is that they require high temperature processing $\left(>400^{\circ} \mathrm{C}\right)$ in order to produce waveguides with low propagation losses. As a result, standard $\mathrm{SiN}$ deposition techniques are incompatible with the integration of active devices in multilayer platforms because their fabrication requires processes that are sensitive to high temperatures such as metallisation and doping.

To address this situation, we propose hot wire chemical vapour deposition (HWCVD) as a mean to deposit $\mathrm{SiN}$ layers at temperatures below $400^{\circ} \mathrm{C}$ for waveguiding applications. HWCVD is a deposition technique based on the catalytic decomposition of reactive gases on filaments heated at temperatures between $1400^{\circ} \mathrm{C}$ and $2000^{\circ} \mathrm{C}(1)$. Therefore, as the decomposition of the reactive species occurs on the filaments, the substrate itself does not have an active role in the reaction and, so, films can be grown at substrate temperature even below $200^{\circ} \mathrm{C}(2)$. Moreover, this technique has proven to be useful to produce amorphous SiN layers with low hydrogen content and high mass density for solar cell applications $(3,4,5)$. This low hydrogen content is imperative to obtain low propagation losses in waveguides operating in the telecom region as most of the losses come from hydrogen impurities, in the form of $\mathrm{N}-\mathrm{H}$ and $\mathrm{Si}-\mathrm{H}$ bonds that act as absorptions centres. 


\section{Method}

In this work, several recipes were defined with a design of experiments methodology in which different combinations of ammonia flow $\left(\mathrm{NH}_{3}\right)$ and filament temperatures (TF) were investigated. The SiN layers were grown using the Echerkon Nitor 301 system on 6" p-type Si wafers at a maximum processing temperature of $350^{\circ} \mathrm{C}$, pressure of $0.033 \mathrm{mbar}$ and $\mathrm{SiH}_{4}$ flow of $6 \mathrm{sccm}$. The physical and optical properties of the obtained SiN layers were characterised using ellipsometry, scanning electron microscopy (SEM), Fourier transform infrared spectrometry (FTIR) and atomic force microscopy (AFM). The propagation losses of the studied materials were measured at 1310 and $1550 \mathrm{~nm}$ using the cutback method with waveguides of different length that were defined using e-beam lithography and transferred to the SiN layer using ICP etching with a chemistry containing $\mathrm{SF}_{6}$ and $\mathrm{CHF}_{3}$.

\section{Results and Discussion}

In terms of the material quality, SEM images (Fig. 1) show that the deposited films exhibit a porous structure with a high density of microcolumns. This structure is typical of amorphous layers, however the high density of microcolumns can be the result of the lower substrate temperature and the lower energy that reactive species have when arriving to the substrate because of the nature of the deposition.

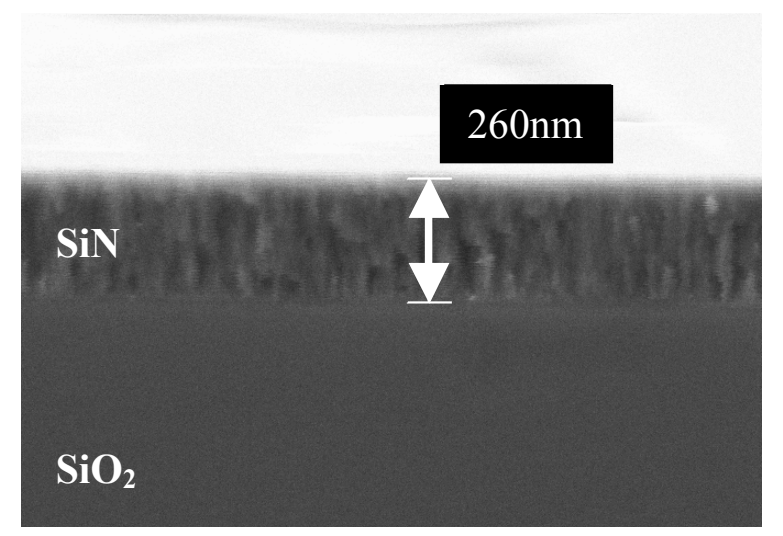

Figure 1. SEM example of the grown SiN layers.

Concerning to the surface properties of the films, ellipsometry measurements show that different layers exhibit a similar thickness uniformity pattern with overall wafer non-uniformity values as low as 5\% regardless of the deposition recipe. These observations suggest that the uniformity of the obtained layers is mostly affected by the geometry of the reactor and that it cannot be related to the deposition parameters that were studied. On the contrary, AFM and FTIR measurements demonstrate that the roughness of the deposited films is directly related to their N/Si ratio that increases whenever the $\mathrm{NH}_{3}$ or TF are incremented as shown in Fig. 2 (a). In fact, the obtained results prove that the roughness is somehow related to the hydrogen content of the films, which keeps a similar intrinsic relation with their N/Si ratio (Fig. 2 (b)). In this case, the lowest roughness of $0.61 \mathrm{~nm}$ was obtained with the film that had the lowest hydrogen concentration of $10.4 \times 10^{21}$ atoms $/ \mathrm{cm}^{3}$ and the $\mathrm{N} / \mathrm{Si}$ ratio closest to the stoichiometric value of 1.3 
As regards to the optical losses of the films, the results indicate that the propagation losses of the fabricated waveguides have an intrinsic relation with their N/Si ratio similar to the ones exhibited by their roughness and hydrogen content (Fig. 2 (c)). As a matter of fact, the lowest losses of $7.1 \mathrm{~dB} / \mathrm{cm}$ at $1310 \mathrm{~nm}$ and $12.3 \mathrm{~dB} / \mathrm{cm}$ at $1550 \mathrm{~nm}$ were obtained with the sample that had the N/Si ratio closest to stoichiometry. As a result, these observations suggest that most of the losses in this sample come from the structure of the material because it had both the lowest roughness and lowest hydrogen content which are the two other properties that can affect directly the losses of the waveguides.
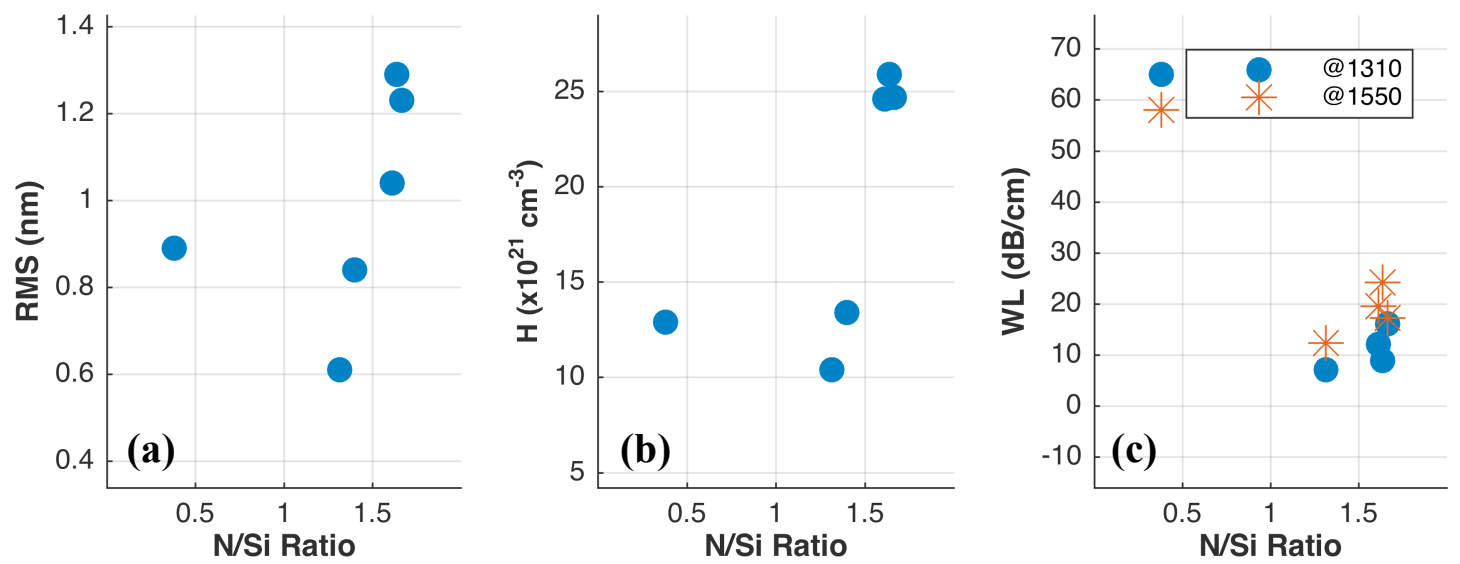

Figure 2. (a) RMS roughness, (b) hydrogen concentration and (c) propagation losses as a function of N/Si Ratio of different HWCVD SiN layers.

\section{Conclusion}

In this work, we have demonstrated the fabrication of waveguides with propagation losses of $7.1 \mathrm{~dB} / \mathrm{cm}$ at $1310 \mathrm{~nm}$ and $12.3 \mathrm{~dB} / \mathrm{cm}$ at $1550 \mathrm{~nm}$ on $\mathrm{SiN}$ films grown by HWCVD that exhibited good thickness uniformity and low surface roughness. The obtained results show that the properties of the deposited SiN layers are mostly affected by their N/Si ratio, which increases in a directly proportional way with the $\mathrm{NH}_{3}$ flow and filament temperature. The observations suggest that the lowest roughness and hydrogen content are obtained with nearly stoichiometric films. However, the quality of the layers must be improved to achieve lower propagation losses. Future work will focus on studying the effect of other deposition parameters to enhance the quality of the grown materials in order to decrease their propagation losses for photonic applications.

\section{References}

1. R. E. Schropp, ECS Trans., 25(8), 3 (2009).

2. P. Alpium, L. M. Gonçalves, E. S. Marins, T. M. R. Viseu, S. Ferdov, and J. E. Bourée, Thin Solid Films, 517(12), 3503 (2009).

3. H. D. Goldbach, C. H. M. van der Werf, A. Scarfo, A. M. C. Kylner, B. Stannowski, W. M. Arnoldbik, A. W. Weeber, H. Rieffe, W. J. Soppe, J. K. Rath, and R. E. Schropp, in Conf. Rec. IEEE Photovoltaic Spec. Conf., p. 1249, IEEE (2005). 
4. J. K. Holt, D. G. Goodwin, A. M. Gabor, F. Jiang, M. Stavola and H. A. Atwater, Thin Solid Films, 430 (1-2), 37 (2003).

5. V. Verlaan, R. Bakker, C. H. M. van der Werf, Z. S. Houweling, Y. Mai, J. K. Rath, and R. E. Schropp, in Surface and Coatings Technologies, 201, p. 9285, Proc. Eur. Conf. Chem. Vap. Deposition, (2007). 